\title{
Patterns of Blood Supply and Venous Drainage in Pediatric Intralobar Pulmonary Sequestration: A Retrospective Analysis of 30 Pediatric Cases from a Single Center
}

\author{
Toshiko Takezoe1, Kazunori Tahara1, Toshihiko Watanabe1, Michinobu Ohno', Kazuteru Kawasaki2,

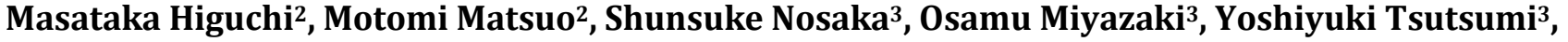 \\ Yutaka Kanamori ${ }^{*}$ \\ ${ }^{1}$ Division of Surgery, Department of Surgical Specialties, National Center for Child Health and Development, Tokyo, Japan \\ ${ }^{2}$ Division of Pulmonology, Department of Medical Subspecialties, National Center for Child Health and Development, Tokyo, Japan \\ ${ }^{3}$ Department of Radiology, National Center for Child Health and Development, Tokyo, Japan \\ Email: *kanamori-y@ncchd.go.jp
}

How to cite this paper: Takezoe, T., Tahara, K., Watanabe, T., Ohno, M., Kawasaki, K., Higuchi, M., Matsuo, M., Nosaka, S., Miyazaki, O., Tsutsumi, Y. and Kanamori, Y. (2016) Patterns of Blood Supply and Venous Drainage in Pediatric Intralobar Pulmonary Sequestration: A Retrospective Analysis of 30 Pediatric Cases from a Single Center. Open Journal of Pediatrics, 6, 274279.

http://dx.doi.org/10.4236/ojped.2016.64038

Received: September 29, 2016

Accepted: October 31, 2016

Published: November 3, 2016

Copyright $\odot 2016$ by authors and Scientific Research Publishing Inc. This work is licensed under the Creative Commons Attribution International License (CC BY 4.0). http://creativecommons.org/licenses/by/4.0/

\begin{abstract}
Purposes: Intralobar pulmonary sequestration is a rare congenital anomaly that causes nonspecific respiratory symptoms. This report presented our surgical experience for pediatric cases of intralobar pulmonary sequestration in our institute. Methods: Between 2002 and 2014, 30 pediatric patients with intralobar pulmonary sequestration underwent lobectomy. The clinical characteristics of patients were retrospectively analyzed using medical records and imaging data. Results: The median age at operation was 23 months. The sequestered lung was situated in the right lower lung in 15 cases and in the left lower lung in 15 cases. Eight cases were prenatally diagnosed by fetal ultrasound and magnetic resonance imaging. One aberrant artery was seen in 26 cases and two aberrant arteries in 4 cases. The drainage vein from the sequestered lung was: 1 ) the pulmonary vein in 27 cases; 2 ) the inferior vena cava in 1 case; and 3) the azygos vein and the pulmonary vein in 2 cases. All patients underwent lower lobectomy of the affected side without postoperative early and long-term complications. Conclusion: Due to the increased rate of prenatal diagnoses, the age at operation has decreased. With respect to safety, it is vital to ascertain the number of aberrant arteries and the venous drainage route before lobectomy.
\end{abstract}

\section{Keywords}

Intralobar Pulmonary Sequestration, Aberrant Artery, Prenatal Diagnosis 


\section{Introduction}

Pulmonary sequestration is a relatively rare congenital lung malformation that accounts for between $0.15 \%$ and $6.4 \%$ of all congenital pulmonary malformations [1]. It is classified into two types, extralobar sequestration (ELS) and intralobar sequestration (ILS). ELS is separated from normal lung tissue by its visceral pleura, whereas ILS is incorporated within normal lung tissue [2]. In both ILS and ELS, the sequestered lung is supplied by anomalous arteries (aberrant arteries) from the systemic circulation [3]. Aberrant arteries usually arise directly from the aorta, but they may also originate from the intercostal, subclavian or celiac artery. If repetitive infections occur in the sequestered lung tissue, spreading inflammation makes it very difficult to obtain an adequate operative view. Therefore, to ensure safety, it is important to collect comprehensive preoperative information on the site of the sequestered lung, the number of aberrant arteries, and the route of the draining vein.

In this study, a retrospective analysis was conducted to examine the clinical characteristics of 30 pediatric patients who received a lobectomy for ILS over the last 13 years. The rate of prenatally diagnosed case is $27 \%$, which is higher than that reported before. The characteristics of the aberrant vessels in our series are almost the same as those in the past large series.

\section{Methods}

The study population was composed of 30 pediatric ILS patients who underwent lobectomy of the affected lung at our center between March 2002 and December 2014. Chest computed tomography (CT) and aortography were performed in all patients to gather detailed information on the locus of the lesion, the aberrant arteries, and the drainage veins. In case to need the more information of the abnormal vessels, selective arteriography such as aberrant arteriography was added. These examinations were done by the radiologists following the principle of "ALARA (as low as reasonably achievable)". A retrospective analysis was conducted using data from medical records and imaging examinations, as follows: Age, gender, affected lobe, past history of pneumonia, age at the operation, the number of the aberrant arteries, venous drainage from the ILS, and postoperative respiratory function.

\section{Results}

Between 2002 and 2014, a total of 30 pediatric patients with ILS, including 10 males and 20 females, underwent lobectomy. The age at operation ranged from 11 months to 124 months (median, 23 months). Eight (27\%) cases were prenatally diagnosed. Without exception, the sequestered lung was located at the lower lobe. The lesions were at the left lower lobe and the right lower lobe in 15 cases each. There were 20 cases (67\%) with a history of pneumonia before the lobectomy and no patient had respiratory distress before operation, but all 30 cases had an uneventful recovery after the operation (Table 1). 
As depicted in Figure 1, the sequestered lung was supplied by a single aberrant artery in 26 cases (87\%), and by two aberrant arteries in the other four cases (13\%). A single aberrant artery from the abdominal aorta was found in 11 cases (37\%), whereas two aberrant arteries from the abdominal aorta were observed in three cases (10\%; Figure 2 (a) and Figure 2(b)). Four cases (13\%) had a single aberrant artery originating from the celiac artery. A single aberrant artery from the thoracic aorta was found in 11 cases (37\%). One case (3.3\%) had two aberrant arteries from the thoracic aorta.

In 27 cases, the drainage vein from the sequestered lung flowed into the lower pulmonary vein (90\%; Table 2). Venous return from the affected lung was via the inferior vena cava in one case (3.3\%; Figure 3(a)), and the pulmonary vein and azygos vein in two cases (6.3\%; Figure $3(\mathrm{~b}))$.

All patients underwent lower lobectomy of the affected side. No postoperative complications occurred and no long term complication was experienced in each patients.

Table 1. Patient characteristics $(n=30)$.

\begin{tabular}{cc} 
Gender & Male 10:Female 20 \\
Affected side & Right 15:Left 15 \\
Localization of the Lesions & Lower Lobe 30 \\
History of Pneumonia & $20(67 \%)$ \\
Prenatal diagnosis & $8(27 \%)$ \\
Median age at the operation & 23 Months \\
\hline
\end{tabular}

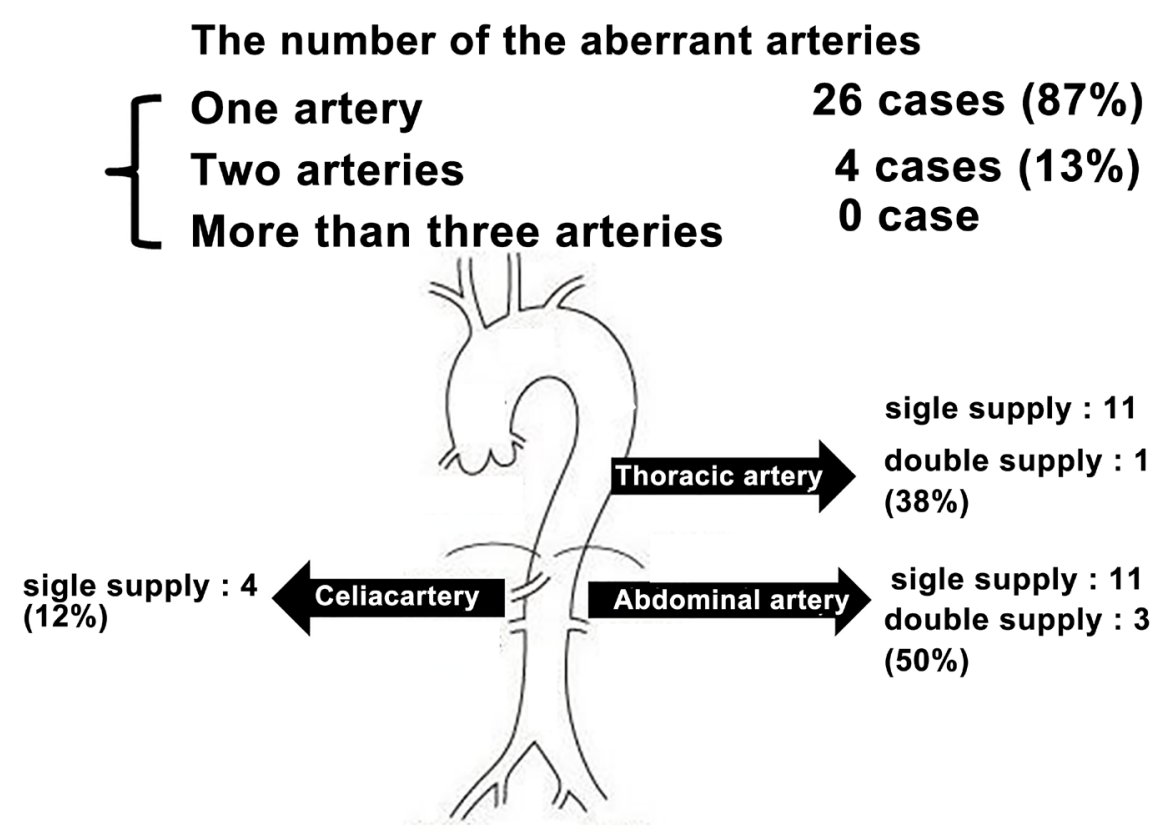

Figure 1. The number and origin of the aberrant arteries in 30 ILS cases. One aberrant artery was seen in 26 cases and two aberrant arteries in 4 cases. The origin of the aberrant artery was classified into three types: 1 ) the thoracic aorta in 12 cases; 2 ) the abdominal aorta in 14 cases; and 3 ) the celiac artery in 4 cases. 

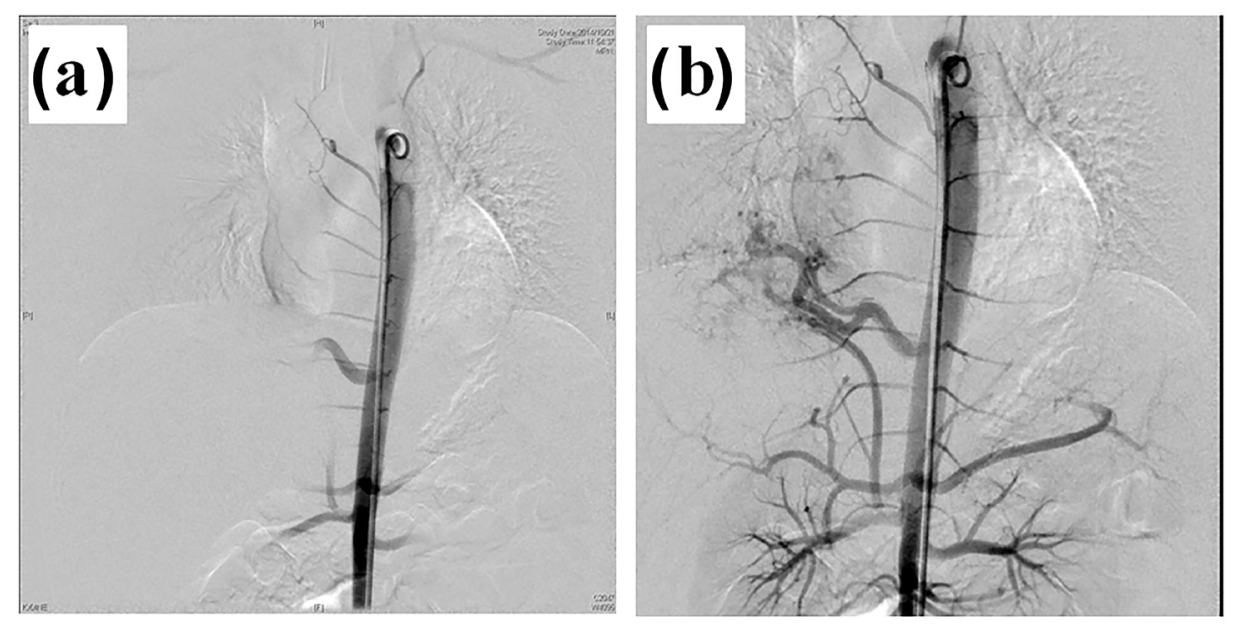

Figure 2. (a), (b) Aortography of a representative case. The images revealed two aberrant arteries that branched at (a) the upper abdominal aorta; and (b) the abdominal aorta nearby the right renal artery.

Table 2. Drainage veins of the sequestered lung.

\begin{tabular}{cc}
\hline To pulmonary vein only & 27 cases $(90 \%)$ \\
To inferior vena cava & 1 case $(3.3 \%)$ \\
To pulmonary vein and azygos vein & 2 cases $(6.7 \%)$ \\
\hline
\end{tabular}
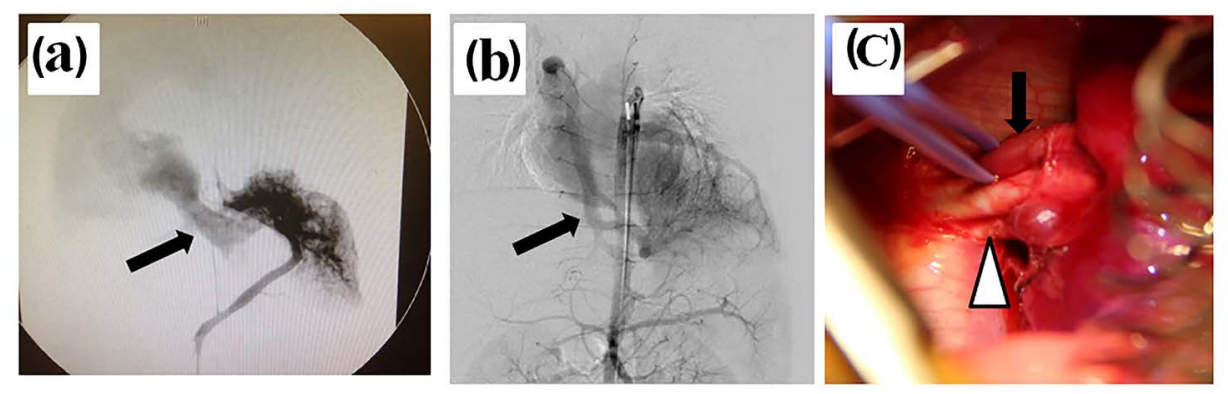

Figure 3. Drainage vein from the sequestered lung, (a) Drainage vein into the inferior vena cava (b) drainage vein into the azygos vein and inferior pulmonary vein; (c) intraoperative image shows two aberrant arteries (white arrow head), and one drainage vein encircled by vessel tape (black arrow) that flows into the azygos vein. It is important to be aware that these three vessels run alongside each other within the pulmonary ligament.

\section{Discussion}

Pulmonary sequestration was first reported in 1877 by Huber et al., but the name "sequestration" was coined by Pryce in 1946 [3]. The pathogenesis of pulmonary sequestration is attributed to malformation of the lung bud in the early embryonic period, resulting in a separate lung tissue. The sequestered lung has no respiratory function but it has an aberrant arterial supply from the systemic circulation [4]. Recurrent respiratory symptoms, including productive cough, chest pain, fever, hemoptysis and pneumonia, 
are typical complaints in children and adults. The presence of these nonspecific respiratory symptoms usually prompts physicians to investigate for pulmonary sequestration [5] [6].

Here, we reported on a consecutive series of pediatric ILS cases from the last 13 years, which is the largest pediatric case series. The findings are consistent with recent changes in the characteristics of pediatric ILS patients. In particular, prenatal diagnosis by fetal ultrasound and magnetic resonance scanning has become more popular, leading to an increase in the rate of prenatal diagnoses. In this study, $27 \%$ of patients were prenatally diagnosed according to evidence of cystic lung lesions and the existence of an aberrant artery. The median age at operation was 23 months. A previous report demonstrated that ILS is usually diagnosed after the age of 2 years [7] by respiratory symptoms. In our case series, there were eight prenatally diagnosed cases and the median age at operation is apparently lower than that in past reports.

ILS tends to occur in the medial or posterior basal segments of the lower lobe, and it is slightly more common in the left lung than the right [7]. However, in our series, there was an equal distribution with respect to the affected side. Also, there were twice as many females than males, whose result was not consistent with the past reports [8].

The standard treatment for ILS is lobectomy of the sequestered lesion. In the majority of cases, ILS is characterized by the presence of a single aberrant artery from the aorta and a single drainage vein towards the pulmonary vein. For the safety of the lobectomy procedure, it is very important to preoperatively ascertain the number of aberrant arteries and the venous drainage route. Based on this view, in the authors' clinic, chest $\mathrm{CT}$ and aortography are routinely used to precisely identify the blood supply and drainage route, and the results are very useful. Recently computer tomographic angiography has been reported as a useful diagnostic method in ILS [8]. But in our series aortography was performed in all cases because chest CT did not always enable clear visualization of the drainage veins and the small aberrant arteries of the pediatric patients, especially the infants.

With regard to arterial supplies, Wei et al. reported that 130 of 813 cases (15.99\%) had two aberrant arteries, while 40 of 813 cases (4.92\%) had more than three aberrant arteries [6]. In our series, the numbers of aberrant arteries were similar in proportion to Wei's study. Of note, the incidence of two or three aberrant arteries in ILS is $10 \%$ to $20 \%$ [6] [9] [10].

In contrast to the venous drainage patterns observed in the present study, Savic et al. found that only 19 of 373 ILS cases (5\%) had a venous outflow other than the pulmonary vein [9]. An analysis by Jotsuka et al. of Japanese studies published over a 10-year period indicated that only 3 of 92 cases (3.2\%) of ILS had systemic venous drainage [10]. In our study, $10 \%$ of cases had drainage veins toward the systemic circulation. This incident rate is important to bear in mind when treating ILS because drainage to the systemic circulation flows parallel to the aberrant artery (Figure 3(c)) and unexpected bleeding may occur if the vessel is not identified.

This paper summarized the experience in one institute and only 30 cases were sur- 
veyed. In this point it is difficult to get a universal character of pediatric ILS from our data, but we concluded that it is very important to determine the pattern of blood supply and venous drainage in ILS to ensure safe operative procedures. For that reason, preoperative assessment using chest CT and aortography may be important and useful for pediatric surgeons.

\section{Conflict of Interest}

The authors have no conflict of interest.

\section{References}

[1] Kestenholz, P.B., Schneiter, D., Hillinger, S., Lardinois, D. and Weder, W. (2006) Thoracoscopic Treatment of Pulmonary Sequestration. European Journal of Cardio-Thoracic Surgery, 29, 815-818. http://dx.doi.org/10.1016/j.ejcts.2006.02.018

[2] Genç, O., Gürkök, S., Dakak, M., Gözübüyük, A., Özkan, M. and Çaylak, H. (2006) Pulmonary Sequestration and Surgical Treatment. Asian Cardiovascular and Thoracic Annals, 14, 3-6. http://dx.doi.org/10.1177/021849230601400102

[3] Pryce, D.M. (1946) Lower Accessory Pulmonary Artery with Intralobar Sequestration of Lung: A Report of Seven Cases. Journal of Pathology, 58, 457. http://dx.doi.org/10.1002/path.1700580316

[4] Marks, C., Wiener, S.N. and Reydman, M. (1972) Pulmonary Sequestration. Chest, 61, 253-257. http://dx.doi.org/10.1378/chest.61.3.253

[5] Buntain, W.L., Wooley, M.M., Mahour, G.H., Isaacs Jr., H. and Payne Jr., V. (1977) Pulmonary Sequestration in Children: A Twenty-Five Year Experience. Surgery, 81, 413-420.

[6] Wei, Y. and Li, F. (2011) Pulmonary Sequestration: A Retrospective Analysis of 2625 Cases in China. European Journal of Cardio-Thoracic Surgery, 40, e39-e42. http://dx.doi.org/10.1016/j.ejcts.2011.01.080

[7] Fumino, S., Iwai, N., Kimura, O., Ono, S. and Higuchi, K. (2007) Preoperative Evaluation of the Aberrant Artery in Intralobar Pulmonary Sequestration Using Multidetector Computed Tomography Angiography. Journal of Pediatric Surgery, 42, 1776-1779. http://dx.doi.org/10.1016/j.jpedsurg.2007.07.028

[8] Tashtoush, B., Memarpour, R., Gonzalez, J., Gleason, J.B. and Hadeh, A. (2015) Pulmonary Sequestration: A 29 Patient Case Series and Review. Journal of Clinical and Diagnostic Research, 9, 5-8.

[9] Savic, B., Birtel, F.J., Tholen, W., Funke, H.D. and Knoche, R. (1979) Lung Sequestration: Report of Seven Cases and Review of 540 Published Cases. Thorax, 34, 96-101. http://dx.doi.org/10.1136/thx.34.1.96

[10] Jotsuka, T., Matsuguma, H., Sawafuji, M., Yokoi, K., Hirose, K., Mori, K., Tominaga, Y. and Imura, J. (1998) Intralobar Pulmonary Sequestration with Three Aberrant Arteries: A Case Report and Review of the Japanese Literature. Kyobu Geka, 51, 142-146. 
Submit or recommend next manuscript to SCIRP and we will provide best service for you:

Accepting pre-submission inquiries through Email, Facebook, LinkedIn, Twitter, etc. A wide selection of journals (inclusive of 9 subjects, more than 200 journals)

Providing 24-hour high-quality service

User-friendly online submission system

Fair and swift peer-review system

Efficient typesetting and proofreading procedure

Display of the result of downloads and visits, as well as the number of cited articles

Maximum dissemination of your research work

Submit your manuscript at: http://papersubmission.scirp.org/

Or contact ojped@scirp.org 